\title{
Transformações e Moldagem Recíproca na Produção Matemática On-line com Software
}

Daise Lago Pereira Souto daise@unemat.br

Universidade do Estado de Mato Grosso, Cuiabá, Mato Grosso, Brasil.

\section{RESUMO}

O presente artigo apresenta uma discussão a respeito do papel de um software nas possíveis transformações e no processo de moldagem recíproca que podem ocorrer durante a produção de conhecimento. Especificamente aborda a ocorrência de ambos durante a produção matemática de professores que utilizam o software dinâmico GeoGebra para estudar as cônicas em um ambiente on-line. A fundamentação teórica está pautada no conceito de Transformação Expansiva advindo da Teoria da Atividade e no construto teórico seres-humanos-com-mídias que discute a noção de moldagem recíproca. A análise dos dados é de cunho qualitativo e está baseada no exame de dados empíricos produzidos em um curso de extensão on-line ofertado por uma universidade pública brasileira a professores de matemática do Brasil e do exterior. Os resultados indicaram que as transformações na produção matemática dos sujeitos estão inextricavelmente relacionadas ao processo de moldagem recíproca e aos distintos papéis que o software desempenhou.

PALAVRAS-CHAVE: Produção Matemática on-line. Teoria da Atividade. Seres-humanoscom-mídias. 


\section{INTRODUÇÃO}

A sociedade atual protagoniza reconfigurações do saber provenientes de novas formas de se pensar e produzir conhecimento, as quais consideram as tecnologias digitais um elemento chave. Auxiliar na compreensão dessas novas configurações e contribuir para uma perspectiva coletiva de se fazer educação matemática nos mobilizou a escrever esse artigo, que tem como objetivo: discutir a respeito de transformações que podem ocorrer no processo de produção matemática de professores que utilizam o software dinâmico GeoGebra para estudar as cônicas em um ambiente on-line.

A hipótese de que não se produz matemática em ambientes on-line já foi refutada por várias pesquisas (e.g. SANTOS, 2006; BAIRRAL, 2005; MALHEIROS, 2008; BORBA, MALHEIROS; AMARAL, 2011). Esses autores destacam que a produção matemática acontece sim nesse tipo de ambiente, mais que isso, ela se modifica em face aos diferentes espaços comunicativos disponíveis. Isso porque se pressupõe que a comunicação é um dos aspectos que fazem parte do processo. Assim, comunicar a linguagem matemática via chat, por exemplo, exige adaptações / mudanças / transformações de seus símbolos para a linguagem materna.

Neste artigo almeja-se discutir outro viés das transformações que podem ocorrer na produção matemática on-line; o foco aqui é o papel do software e sua influência no processo. Para tanto, na análise dos dados buscamos um enfoque qualitativo pautado no conceito de transformação expansiva proveniente da teoria da atividade (ENGESTRÖM, 1987, 1999) e na visão de conhecimento associada ao construto teórico seres-humanos-com-mídias (BORBA, 1993, 1999; BORBA; VILLARREAL, 2005).

O contexto de produção dos dados foi um curso de extensão universitária, considerado tradicional e um dos pioneiros na área, pois vem sendo ofertado desde 1993 por uma universidade pública brasileira localizada no estado de São Paulo e que tem como público alvo professores de matemática do Brasil e do exterior.

Para cumprirmos com o objetivo proposto optamos em estruturar o presente artigo da seguinte forma: inicialmente apresentamos os fundamentos teóricos, explicitando os conceitos que permeiam a Teoria da Atividade, com particular destaque às ideias de Engeström $(1987,1999)$, que especifica a necessidade de se compreender as relações e transformações que ocorrem dentro de contextos coletivos. Nesta mesma seção, já vamos abordando os conceitos que envolvem o constructo Seres-humanos-com-mídias, que sugere a produção do conhecimento, no âmbito da educação matemática, como sendo o resultado de trocas recíprocas entre humanos e mídias. $O$ intuito dessa aproximação é fazer com que se perceba que os pensamentos que circundam esses referenciais estão próximos, se harmonizam e potencializam as discussões aqui almejadas. Na sequência, expõese o contexto de produção dos dados e os aspectos metodológicos desse trabalho. Por fim, realizamos a análise dos dados e, em seguida, tecemos nossas considerações finais. 


\section{OS FUNDAMENTOS TEÓRICOS E SEUS LAÇOS}

Um dos fundamentos teóricos que adotamos é a Teoria da Atividade, que possui traços do pensamento vygostykyano e fundamentos filosóficos baseados nos trabalhos de Karl Marx e Friedrich Engels.

Essa teoria, ao mesmo tempo em que se desenvolve, se ramifica em diferentes abordagens originadas, principalmente, pelas diferentes opiniões que seus estudiosos têm em relação à unidade de análise, se esta deve ser considerada em uma perspectiva coletiva ou não. No entanto, em sua gênese a atividade humana é tomada como base do desenvolvimento humano e em seu eixo central, ocupando um lugar de destaque, se encontram as transformações que podem ocorrer nas interações que se estabelecem entre o ser humano e o ambiente no desenvolvimento de atividades mediadas por artefatos .

Dentre as diferentes ramificações dessa teoria optamos em fundamentar este artigo no trabalho de Engeström (1987, 1999), pois, como comentamos anteriormente, nosso intuito é contribuir para uma perspectiva coletiva de se fazer educação matemática.

Esse autor explica a teoria da atividade apoiado na ideia de uma unidade coletiva de análise (fig. 1) em conjunto com outros princípios, quais sejam: multivocalidade (múltiplas vozes que emergem dos participantes da atividade); historicidade (qualquer sistema de atividade deve ser analisado à luz de sua história); contradições internas (tensões ou desequilíbrios inerentes a qualquer atividade) e transformações expansivas (reconceitualizações dos elementos da atividade, em particular do objeto).

A unidade de análise para esse autor é uma organização sistêmica e coletiva, que ele representa por meio do diagrama triangular apresentado na figura 1.

Figura 1: Representação do sistema de atividade humana

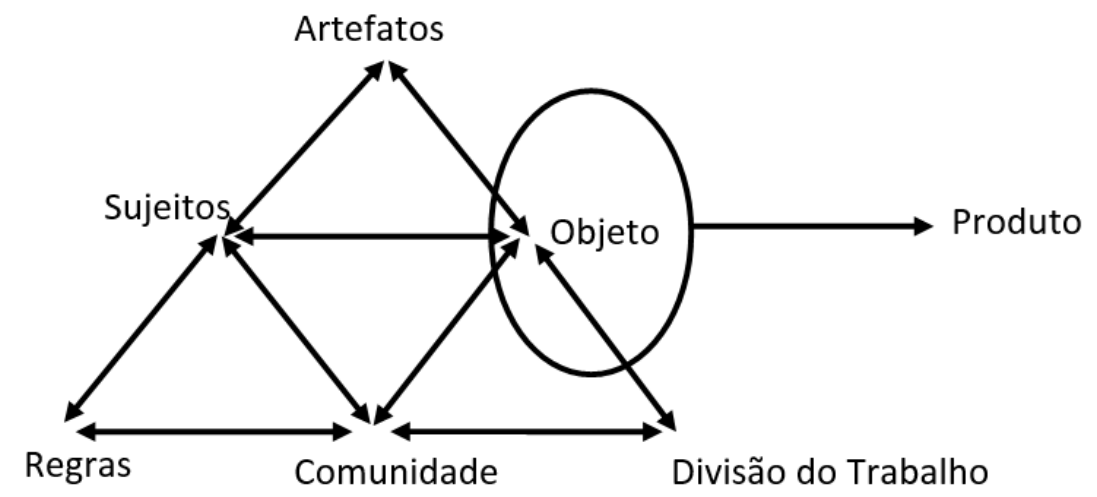

(Fonte: ENGESTRÖM , 2001)

Essa representação triangular tem raízes no pensamento vygotskyano, o qual defende que a relação do homem com o mundo não é direta e sim mediada por artefatos. Ela também tem influência dos fundamentos indicados por um discípulo de Vygostsky: Leontiev (1987), que indicou inicialmente a necessidade de se analisar o papel de coletivos humanos em atividade. Assim, com base principalmente nesses teóricos, Engeström (1987) procura estender o conceito de mediação de Vygostky para o contexto cultural. Esse esforço pode ser verificado 
na figura 1; o triangulo superior que tem como vértices sujeitos-artefatos-objeto é uma analogia ao ato complexo defendido por Vygotsky. Os demais triângulos representam a extensão dessa ideia, que nesta perspectiva de unidade coletiva abarca também as relações da comunidade, divisão do trabalho e regras.

Engeström (1987) explica que os princípios propostos por ele não devem ser analisados de forma isolada, por isso elabora uma ferramenta de análise: o ciclo de aprendizagem expansiva ou ciclo de transformações expansivas.

O início do desenvolvimento histórico desse tipo de ciclo geralmente é verificado em meio a crises ou em momentos de dificuldades, em que dúvidas são levantadas ou quando emergem negociações em relação a uma dada prática corrente que já não é mais aceita. Nesse instante já é possível verificar as múltiplas vozes que emergem do sistema, ou seja, os diferentes pontos de vista de cada sujeito participante do sistema de atividade. $\mathrm{O}$ ciclo começa a evoluir quando há a "exigência" de uma mobilização em direção à análise de possíveis soluções para a situação. Com isso, são elaboradas diferentes ideias que expliquem e ofereçam caminhos alternativos para a situação. Parte-se então para a experimentação dessas ideias, com o intuito de se verificar as limitações e potencialidades de cada uma para que assim seja possível escolher a melhor opção. Neste estágio, as rupturas e contradições internas da atividade podem surgir devidas, principalmente, aos diferentes pontos de vistas que emergem da multivocalidade do sistema. Encontrada a melhor solução ou ideia, é hora de implementá-la por meio de aplicação prática. Segue-se então para a reflexão avaliativa na qual a nova prática se consolidada e, com isso, o ciclo se encerra.

É oportuno destacar que um ciclo, neste contexto, não deve ser entendido como movimentos sequenciais que se repetem de forma linear e que se encerra quando retorna ao seu ponto inicial. Ao contrário, aqui enfatizamos o pensamento de Engeström (1987), que descreve um ciclo de aprendizagem expansiva como um movimento em espiral que se desenvolve marcado por relações não lineares.

Em Souto (2013), Souto e Araújo (2014), Souto e Borba (2013), Souto (2014) trouxemos essas ideias para o âmbito da educação matemática, reinterpretamos o conceito de transformações expansivas e propusemos uma adaptação dessa ferramenta analítica para pesquisas nessa área, em particular, aquelas desenvolvidas em ambientes on-line. $O$ trânsito dessas ideias para a Educação Matemática teve uma fundamental contribuição do construto seres-humanoscom-mídias, o qual também expressa nossa visão de conhecimento. Ele nasceu e vêm sendo legitimado nas pesquisas desenvolvidas há mais de 20 anos pelo Grupo de Pesquisa em Informática Outras Mídias e Educação Matemática - GPIMEM .

Em seus fundamentos encontra-se a ideia de que a produção de conhecimento acontece com base em um pensamento coletivo que é construído de forma igualitária por atores humanos e não humanos. Para propor esse construto Borba $(1993,1999)$ se debruçou sobre as discussões teóricas de dois estudiosos: um deles é Tikhomirov (1981), que por sua vez se apoia na própria teoria da atividade para discutir o modo como o pensamento é exercido por sistemas compostos de seres humanos e computadores. O outro é Lévy (1993), que aborda a constituição de coletivos pensantes e a forma como eles têm condicionado diferentes tipos de produção de conhecimento ao longo da história. (BORBA, 1993, 1999; BORBA; VILLARREAL, 2005), que enfatiza a relação ubíqua 
entre seres humanos e mídias na produção de conhecimento. Nela, perpassa a ideia de reorganização do pensamento de Tikhomirov (1981), o que explica a semelhança dessa moldagem com a tese vygotskyana de mediação (SOUTO; ARAÚJO, 2013). No entanto, em Souto e Borba (2015 - manuscrito) esclarecemos que no construto seres-humanos-com-mídias

\footnotetext{
A ideia de mediação é extendida para uma de impregnação mútua, em que as mídias permeiam o humano da mesma forma que as tecnologias são compreendidas como sendo impregnadas por humanidade. A linha do externo-interno se dilui e se torna mais "fuzzi". Conhecimento é pensado como sendo a produção de humanos, mas também por tecnologias historicamente constituídas (SOUTO; BORBA 2014 - manuscrito).
}

Em outras palavras, cremos que é incoerente separar sujeitos e tecnologias, uma vez que se relacionam de modo recíproco, um dependente do outro, formando um polo único que se constitui pelo processo histórico-social (SOUTO, 2013).

Quando reunimos as ideias do construto com as ideias da teoria da atividade apresentadas anteriormente e as trouxemos para o âmbito da educação matemática reinterpretamos o conceito de transformações expansivas como sendo:

Movimentações em um sistema de atividade coletiva em que seres humanos com tecnologias buscam, de forma crítica, um modo que não havia sido em outras situações pensado por eles para compreender e/ou reconstruir entendimentos sobre um determinado problema ou conteúdo matemático (SOUTO, 2014, pg. 154).

Essa é a definição que adotamos neste artigo. Também anunciamos anteriormente a proposição de uma adaptação à ferramenta analítica proposta por Engeström (1987). Optamos em apresentá-la a seguir porque a consideramos como parte dos aspectos metodológicos deste trabalho.

\section{O CONTEXTO DE PRODUÇÃO DOS DADOS, ASPECTOS PEDAGÓGICOS E METODOLÓGICOS}

Os chats, fóruns, relatórios de trabalho e entrevistas que ocorreram no curso de extensão universitária denominado "Tendências em Educação Matemática" ofertado na modalidade a distância on-line são as fontes de produção dos dados deste estudo. A opção por múltiplas fontes é um aspecto que buscamos para dar maior credibilidade a essa pesquisa (LINCOLN; GUBA, 1985; ARAÚJO; BORBA, 2004; GOLDEMBERG, 2004).

Convidamos os professores participantes, todos da área de matemática, a desenvolver, em pequenos grupos, soluções a problemas de cunho matemático voltados para o estudo das cônicas com o software de matemática dinâmica GeoGebra. Para tanto, eles se encontravam no ambiente virtual de aprendizagem Tidia-Ae , que possui ferramentas de comunicação síncronas e assíncronas.

Para alcançarmos uma harmonia entre as dimensões pedagógica, epistemológica e metodológica elaboramos uma proposta pedagógica que favorecia as interações no ambiente virtual, privilegiando o trabalho coletivo, colaborativo e dialógico. Nosso intuito era de aproximarmos o nosso trabalho da 
ideia de "sala de aula interativa" (SILVA, 2003). Esse modelo de proposta para cursos a distância vem sendo desenvolvido ao longo dos últimos 15 anos pelo GPIMEM, enquanto esse grupo vem elaborando e aperfeiçoando a noção de sereshumanos-com-mídias.

Como mencionado anteriormente, a ferramenta de análise que utilizamos foi proposta de Souto $(2013,2014)$ e foi também discutida por Souto e Borba (2013): o Miniciclone de Transformações Expansivas. Essa perspectiva de análise voltada para a educação matemática entrelaça as ideias teóricas, apresentadas anteriormente, do Ciclo de Aprendizagem Expansiva proposto por Engeström (1999) e da noção de moldagem recíproca proposta por Borba $(1993,1999)$.

A ideia central é apresentar uma ferramenta analítica que possa favorecer a compreensão do desenvolvimento histórico de sistemas de atividade, cujo foco seja a produção matemática captando a mutivocalidade, suas contradições internas e a ocorrência de transformações expansivas em ambientes on-line. É oportuno esclarecer que o Miniciclone se diferencia do Ciclo proposto por Engeström, em vários aspectos, os principais são: o curto espaço de tempo em que ele pode se desenvolver, a não necessidade de uma verificação em relação à consolidação da prática e em sua ênfase na produção matemática de uma unidade coletiva formada por atores humanos e mídias.

Um miniciclone pode ser iniciado por meio de dúvidas e/ou questionamentos decorrentes de uma contradição interna (ou tensão), que pode ser uma necessidade de solucionar uma situação nunca antes prevista, um desejo de romper com um padrão de produção Matemática relativamente estável, ou quando procedimentos que estão automatizados e que fazem parte de uma dada prática passam a ser repensados. O miniciclone evolui com base na reorganização do pensamento, que em geral é provocada pelas respostas da mídia às ações dos aprendizes. Nesse processo evolutivo a dinâmica do trabalho pode mudar, movimentos de reorganização podem se intensificar nos testes de conjecturas, experimentações e simulações. Neste momento de instabilidade é possível observar o processo de moldagem recíproca que carrega consigo pistas do objeto da atividade. Durante a moldagem recíproca podem emergir novas tensões, que uma vez revertidas em fonte potência para a inovação originam as transformações expansivas, que por sua vez podem indicar o final do miniciclone. As transformações expansivas são múltiplas e podem ocorrer de formas distintas dependendo, em certa medida, da mídia envolvida na atividade.

É necessário esclarecer que no contexto do desenvolvimento de sistemas de atividade com base em um Miniciclone é difícil, a priori, determinar ou prever com exatidão a direção que ele vai tomar. Entretanto é oportuno destacar que, ele não leva, em geral, o sistema, a um ponto onde a atividade já esteve anteriormente.

\section{A PRODUÇÃO MATEMÁTICA ON-LINE COM O SOFTWARE GEOGEBRA}

A proposta de estudo foi dividida em duas partes: a primeira delas consistia em construir as cônicas com o GeoGebra. Essas construções eram orientadas por uma espécie de tutorial com um passo-a-passo que era enviado com antecedência a todos os participantes. Logo após essas construções havia uma série de questões software. 
Após essas construções, na segunda parte do estudo, propusemos aos participantes a solução de alguns problemas usualmente encontrados em livros didáticos. Por exemplo: 1) Determine o centro, os eixos e os focos da hipérbole ; 2) Dada a equação $y^{2}=-8 x$ trace o gráfico, determine suas coordenadas de foco e a equação da diretriz. Em casos como esses não havia nenhum tipo de orientação sobre a forma como solucioná-los ou sobre o tipo de mídia que deveria ser utilizada.

No decorrer da primeira parte da proposta de estudo das cônicas o GeoGebra desempenhava o papel de artefato (fig. 2).

Figura 2: Geogebra como um artefato

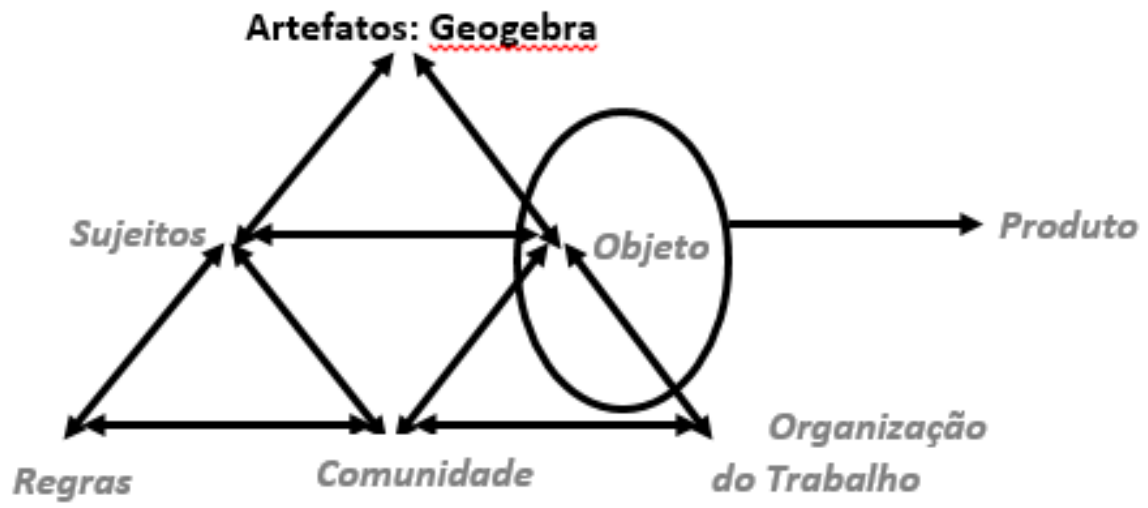

O quadro 1 apresenta, à esquerda, uma parte de um dos relatórios dos professores, em que é possível verificar o GeoGebra desempenhando o papel de artefato conforme está representado na figura 2 e, à direita, uma ilustração da construção que estava em discussão. 
Quadro 1: Construção da parábola

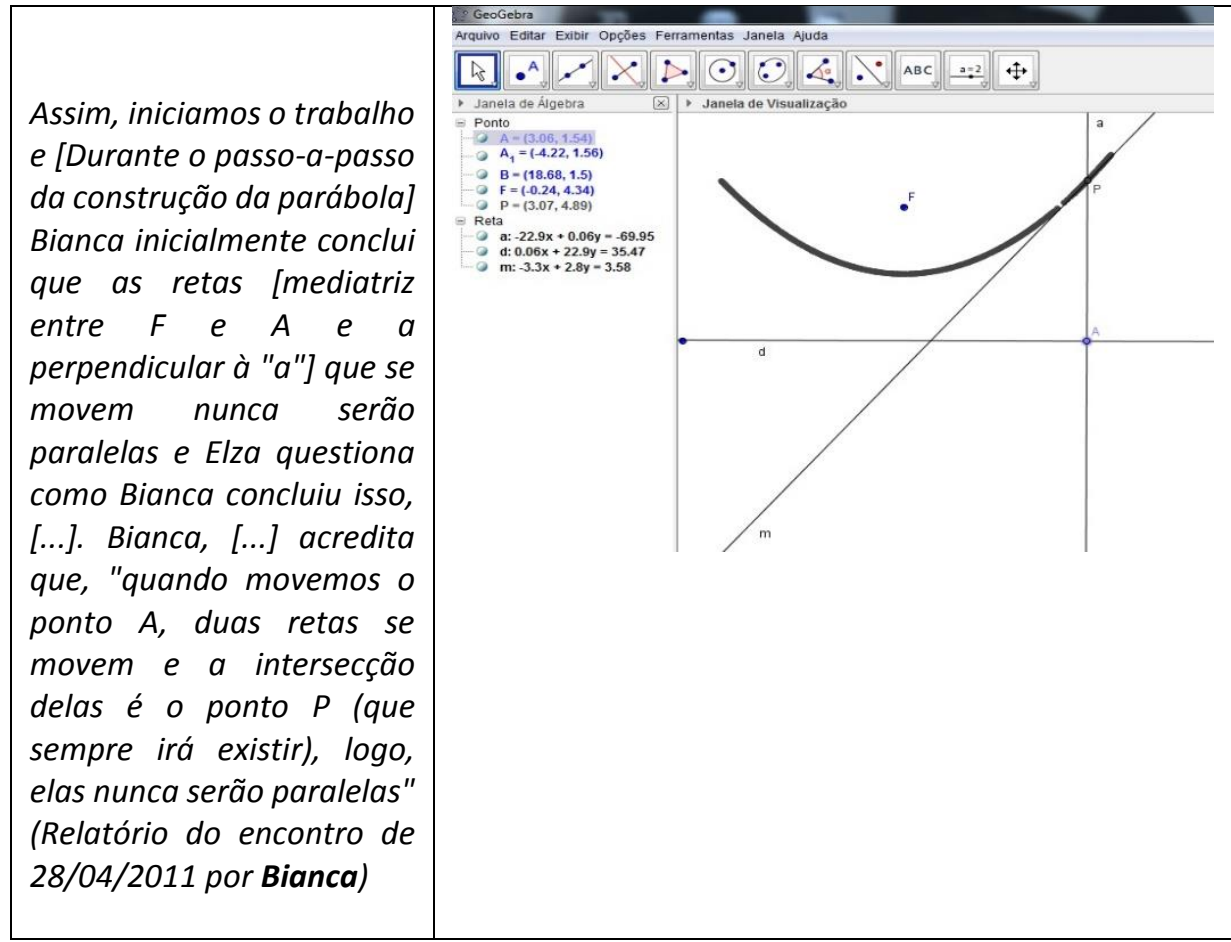

As conjecturas dos professores eram elaboradas com base nos feedbacks do software que suscitou debates e contribuiu para que o raciocínio deles fosse reorganizado. A análise de Bianca, com base no uso do recurso arrastar deixa clara tal reorganização que pode ser entendida como um processo de mediação (TIKHOMIROV, 1981; BORBA, 1993, 1999). Portanto, o GeoGebra pode ser visto como um artefato, pois mediou a relação dos sujeitos com o objeto.

Nesse caso, cabe perguntar: qual é o objeto dessa atividade? De acordo com Engeström (1987) esse elemento deve ser entendido como a matéria-prima ou espaço-problema para o qual o sistema de atividade é dirigido. Ele é um alvo móvel e uma fonte de instabilidade, por isso, sua determinação a priori é um esforço problemático (HARDMAN, 2007), entretanto, necessário porque uma possivel transformação expansiva está na própria ideia de reconceitualização do objeto.

Sendo assim, buscamos em Kaptelinin (2005) alguns indicativos que podem contribuir para uma aproximação inicial do objeto desse sistema. Esse autor esclarece que tal elemento da atividade pode ser determinado por todos os motivos efetivos. Logo, entendemos que alguns depoimentos dos professores nos fóruns revelavam os interesses pessoais em participar do curso, com base nos quais é possível identificar alguns motivos efetivos e, com isso, chegar a uma aproximação do objeto.

Vejo este curso como uma oportunidade de atualizar minha prática docente e talvez até prosseguir no doutorado nessa área (BIANCA).

Os EAD dão oportunidades as pessoas que não tem acessos aos grandes centros, para fazer uma formação[...] e esse curso vai me ajudar muito, a entender a educação a distância, pois aqui em Vila Rica terá um polo da UAB (VÂNIA) 
Os interesses revelados nos comentários acima dão alguns indicativos de que a mobilização para a participação do curso foi fruto de pelo menos dois motivos: construir a identidade de pesquisadores em Educação Matemática e buscar uma capacitação profissional. Tais motivos sugerem que o objeto, naquele instante, estava relacionado com a possibilidade de uma qualificação acadêmica e profissional.

À medida que o trabalho se desenvolvia algumas tensões surgiam, em particular, durante a busca por soluções para os problemas da segunda parte do estudo. Inicialmente os professores adotavam o que pode ser considerado um procedimento padrão para eles, que consiste em encontrar uma solução algébrica utilizando técnicas analíticas conhecidas e que também são usualmente encontradas em livros didáticos. Por outro lado, a parte inicial da proposta de estudo mostrou a eles as possibilidades de uso do GeoGebra para a construção das cônicas. Isso gerou uma tensão (contradição interna) no sistema de atividade que estava se constituindo.

\footnotetext{
Silvia - determine a equação e as coordenadas dos focos de uma elipse de eixo maior 10 e distância focal 6.[...]eu cheguei em $F 1=(-3,0)$; $F 2=(3,0)$, e $x^{\wedge} 2 / 25+y^{\wedge} 2 / 16=1$
}

Thais - Sim, eu também... comecei achando o b pelo teorema de Pitágoras, já que $a=5$ e c=3. [...] daí já sai os focos, e a equação é só montar com esses valores. [...] certo... e como verificar no GeoGebra?

As atividades são sistemas abertos, por isso, a introdução de algo novo, como por exemplo, um novo instrumento, pode ir de encontro a um elemento antigo e, desse modo, provocar tensões (DANIELS, 2011). Nesse caso, o elemento novo é o próprio software, pois ao que parece no excerto acima as possibilidades desse aplicativo tencionaram as formas usuais que os professores participantes organizavam o seu próprio trabalho.

Essa tensão é um indicativo de que o minicilone começou a se desenvolver, pois, como pode ser observado no excerto anterior, o GeoGebra protagonizou uma situação que desestabilizou e imprimiu mudanças no sistema de atividade quando "mexeu" com a forma de produzir Matemática já internalizada por esses professores. Esses movimentos decorrem das reorganizações do pensamento que foram influenciadas pelo próprio aplicativo no início da proposta de estudo (TIKHOMIROV, 1981; BORBA, 1999).

No desenvolvimento desse miniciclone verifica-se que o processo pelo qual o software moldava as ações dos professores se intensificava e o trabalho com esse aplicativo se transformava em um espaço-problema no sentido proposto por Engeström (1987), uma vez que as soluções já não se mostravam triviais e provocavam transformações qualitativas no pensamento coletivo. Esse fato coloca o GeoGebra na condição de objeto do sistema de atividade (fig. 3). 


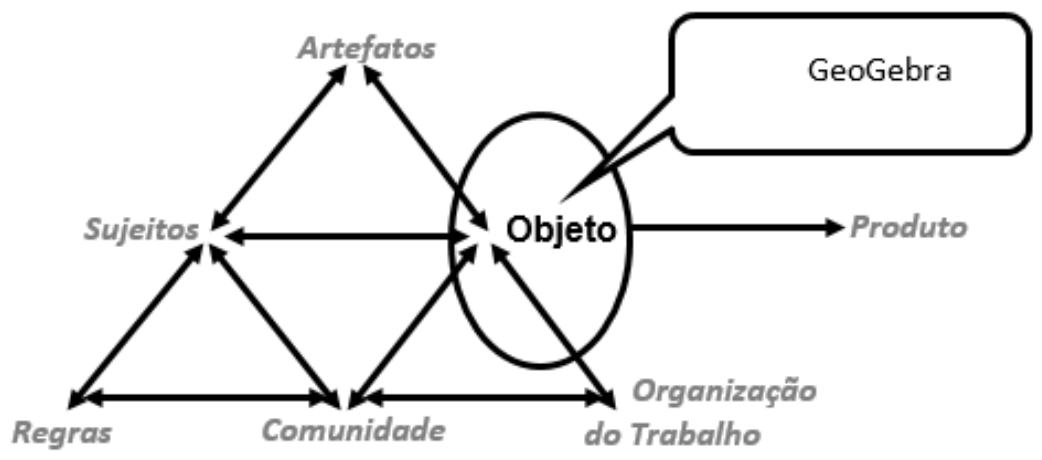

Alguns diálogos que ocorreram durante o estudo da hipérbole, especificamente na discussão do exemplo 1 apresentado no início dessa seção, retratam, em certa medida, que a busca por uma solução com o GeoGebra foi um processo difícil. Esse tipo de discussão também auxilia na compreensão desse novo papel do software destacado na figura 3.

\author{
Thais - e ai Bianca??? Alguma ideia? \\ Bianca - estou ainda fazendo testes... peguei dois possíveis focos (sobrea reta \\ $y=2$ ) e estou testando as distâncias... \\ Thais - vc observou que f1, f2, A e B podem estar alinhados?
Bianca - é?? na verdade precisamos encontrar f1 e f2 ... mas já deu pra mim ... preciso pensar mais.. cansei.

Thais - num desiste não ... please. Poxa Daise ... você judiou. Rs 
Thais - É isso mesmo Francieli ... as ferramentas são muito simples no GeoGebra, mas difícil é articular as ideias matemáticas

Raquel - Concordo com você Francieli, também tive dificuldades em relação à interpretação.

Bianca - Daise ... a dificuldade não foi com o geogebra mas sim de visualização dos parâmetros e encontrar explicação algébrica..

Os excertos anteriores refletem a opinião dos professores em relação ao software no processo de produção Matemática. Quando esses docentes destacaram a dificuldade que tiveram para interpretar e visualizar, estavam se referindo ao processo em que eles buscavam construir relações entre as representações Algébricas e Geométricas que, com o GeoGebra, foi realizada de forma simultânea e dinâmica.

Esses professores a princípio tratavam essas duas formas de representação de forma separada como se fossem "coisas" distintas. No entanto, os recursos desse aplicativo propiciaram um tipo de análise que relacionava essas duas formas de representação e, com isso, despertava outras possibilidades de raciocínio, nunca antes pensado pelos sujeitos da atividade. Nesse sentido, é possível dizer que o software transformou a produção Matemática dos professores participantes do curso.

Além das "falas" desses professores é possível verificar tais transformações nas próprias ações anunciadas durante as discussões nos chats.

Thaísa - calculamos o foco, mas não sabíamos como fazer isso diretamente no geogebra...

Vinicius - vamos inserir uma equação, vamos abrir o algebra (em branco) e colocar $\mathrm{p}=2$ e $\mathrm{x}^{2}=2 * \mathrm{p}^{*} \mathrm{y}$, teremos a parábola passando pela origem. vamos fazer um caso genérico pra aquecer. Depois todo mundo tenta no exemplo proposto pela atividade.

Thaísa - sim...

Vinicius - Após usar vários recursos do Geogebra, decidi fazer uma coisa que sempre falo aos alunos, que às vezes devemos dar um passo para traz para podermos dar muitos outros a frente. (quase nunca faço)

Sandra - ok..rsrsrsrr

Vinicius - Foi o que fiz, voltei ao inicio da atividade 1 e observei algumas coisas: que a reta mediatriz $(\mathrm{m})$ é tangente a parábola, em todos os pontos da parábola mais precisamente. mundo concorda com isso? estão lembrados?

Thais - Sugestão... meninas precisamos descobrir o que tem a ver aqueles a e b nas construções... certo? Podemos fazer isso usando o potencial do software... [...] O GEoGebra é um simulador, então podemos brincar com ele... modificamos os parâmetros e tentamos analisar quais alterações acontecem. Vamos lá!!! 
ideia de que o processo de moldagem recíproca (BORBA, 1993; 1999) pode auxiliar na identificação do objeto da atividade. Os feedbacks do software em resposta às ações dos professores reorganizavam o raciocínio desse coletivo e, dessa forma, moldava as ações futuras. Tais reorganizações implicaram em mudanças nas formas de pensar e de se expressar matematicamente desses docentes, nesse caso, o software pode ser considerado um agente transformador.

No quadro 2 a figura de uma construção geométrica ao lado de uma argumentação matemática ilustram as expansões que ocorreram na produção Matemática desses professores durante o curso, trata-se da solução final do "caso genérico" proposto por Vinícius no excerto anterior.

Quadro 2: construção final do caso genérico

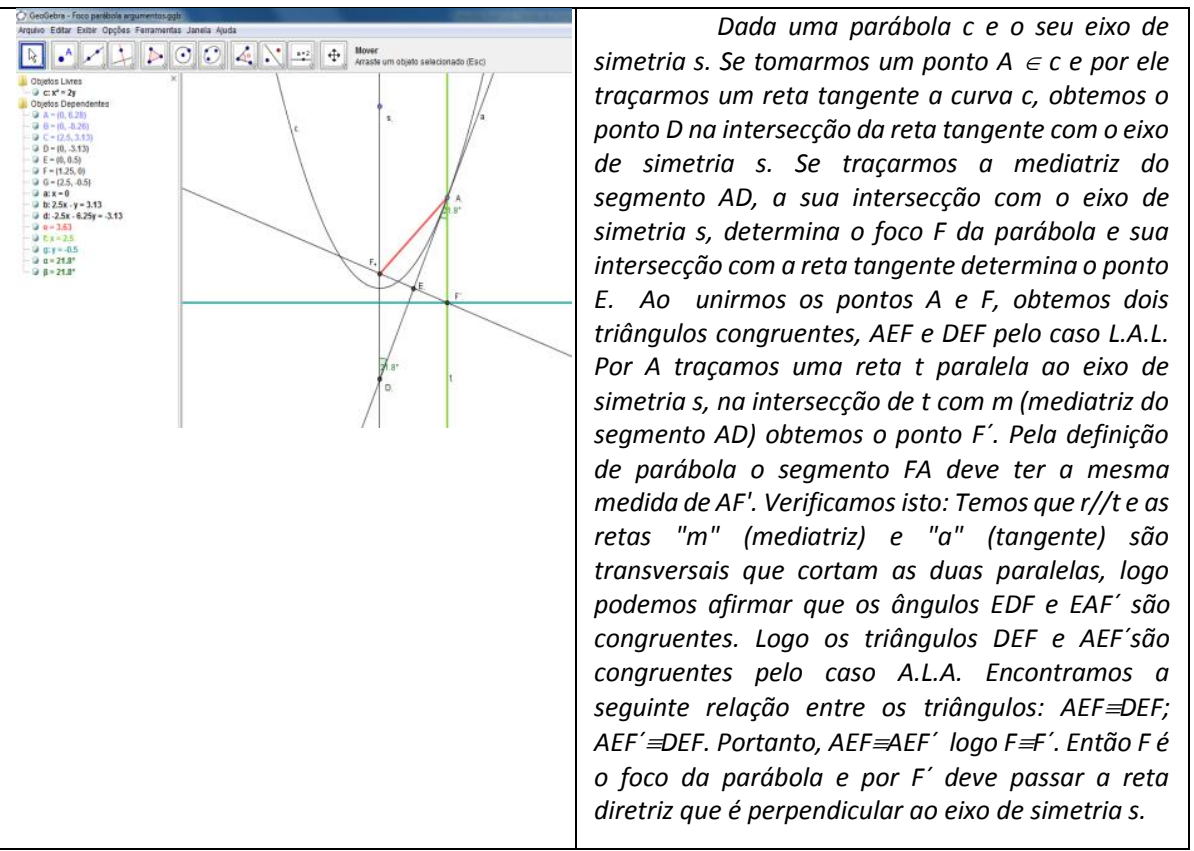

Superando várias tensões que foram surgindo os professores constroem e justificam uma solução geral que pode contribuir para resolver questões específicas como as que foram apresentadas no início dessa análise. Essa etapa do estudo da parábola em que os conceitos do ponto de vista matemático são formalizados mostra que os professores conseguiram estabelecer relações entre as representações Algébricas e Geométricas dessa cônica. Isso pode ser considerado o final de um Miniclone. No entanto, é preciso destacar que um miniciclone se constituiu por meio de movimentos recorrentes, por isso o seu final não indica que o conhecimento produzido esteja fechado ou encerrado, ao contrário, esse conhecimento poderá voltar a ser novamente (re)construído em outros sistemas, em outros contextos e/ou com outras mídias.

Para sistematizar essa análise, os movimentos do GeoGebra são ilustrados na figura 4, em que os dois papéis que essa mídia desempenhou são relacionados ao desenvolvimento do miniciclone, à ocorrência de transformações expansivas no sistema de atividade e ao processo de moldagem recíproca. 


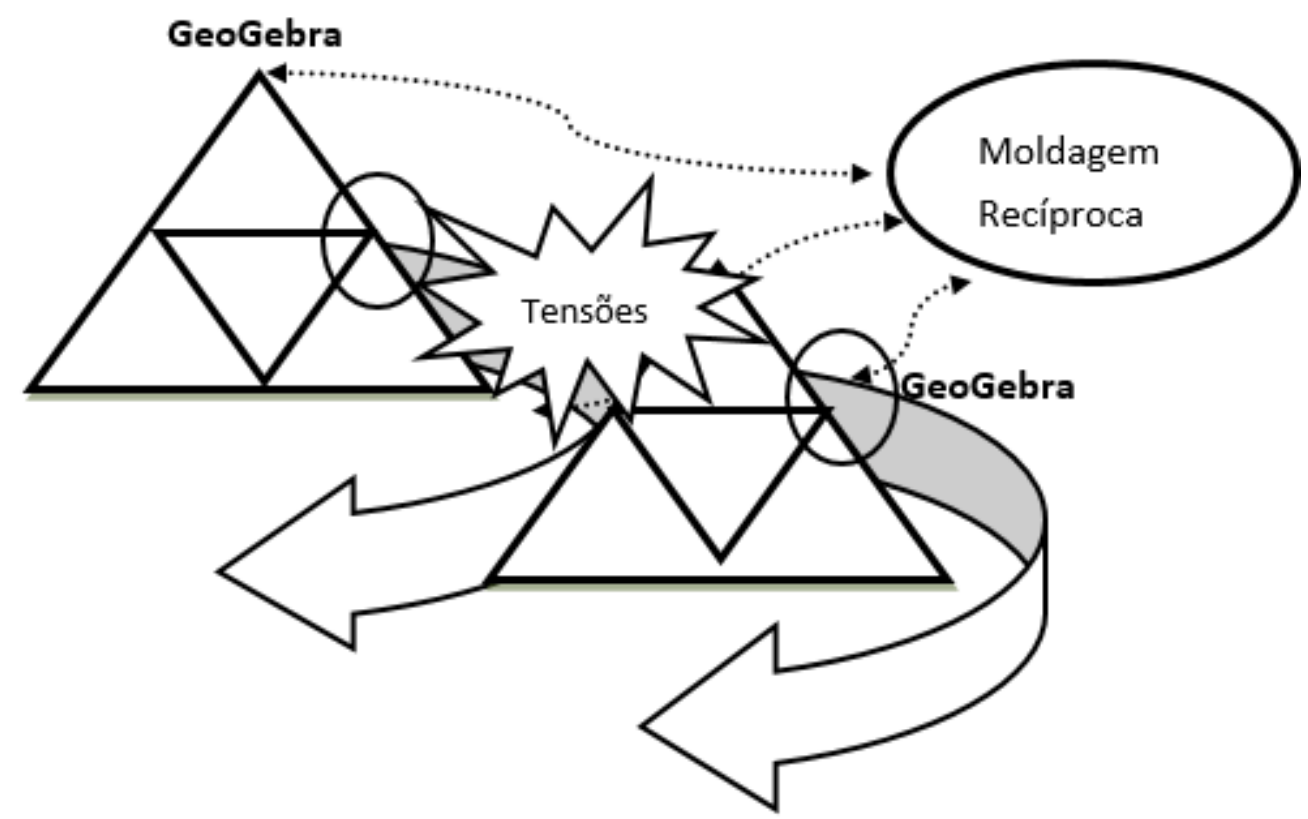

Na figura 4 cada uma das representações triangulares corresponde a um determinado instante do desenvolvimento do sistema de atividade. Na primeira delas o GeoGebra está na condição de artefato mediando as relações dos sujeitos com o objeto que, naquele instante inicial do sistema, estava relacionado à qualificação profissional e acadêmica dos professores participantes. Esse sistema é o correspondente ao início do Miniciclone representado pela primeira seta lateral, que teve início com a tensão causada pela inserção do próprio software feita através da proposta de estudo.

À direita da figura está o processo de moldagem recíproca que é ligado com linhas pontilhadas aos sistemas de atividade, ao Miniciclone e às tensões. Com isso, destaca-se que durante a evolução do processo de moldagem recíproca tensões surgem e podem dar início a um Miniciclone, como também, podem contribuir para que as tensões se transformem expansivamente.

Na segunda representação triangular o próprio software se apresenta como parte do objeto que passou a ser: estudar cônicas com o GeoGebra. Essa representação deve ser vista de forma relacionada com a segunda seta lateral que corresponde ao Miniciclone. Nesse momento, observa-se um avanço no Miniciclone decorrente do próprio processo de moldagem recíproca e de uma nova tensão que surgiu quando os professores procuravam construir com esse aplicativo relações entre as representações algébricas e geométricas. Na figura 4 essa tensão está entre as setas que representam o Miniciclone. medida em que o processo de moldagem recíproca se desenvolveu tensões 
surgiram e se desenvolveram expansivamente. Assim, ocorreu uma transformação expansiva, em que o artefato GeoGebra se torna objeto. Esses movimentos impulsionaram outra transformação, trata-se da própria expansão da produção Matemática dos sujeitos.

\section{CONSIDERAÇÕES FINAIS}

Nosso objetivo, nesse artigo, foi apresentar uma discussão a respeito do papel de um software nas possíveis transformações e no processo de moldagem recíproca que podem ocorrer no processo de produção de conhecimento. Especificamente aborda a ocorrência de ambos durante a produção matemática de professores que utilizam o software dinâmico GeoGebra para estudar as cônicas em um ambiente on-line. Para tanto, nos fundamentamos na teoria da atividade, em particular nas ideias de Engestrom que propõe, entre outros princípios, as transformações expansivas. Outro referencial adotado foi o construto teórico seres-humanos-com-mídias que discute o processo de moldagem recíproca. Os dados foram produzidos em um curso de extensão universitária ofertado na modalidade a distância on-line para professores de matemática, sendo que sua análise seguiu uma orientação qualitativa baseada na ferramenta analítica denominada: miniciclone de transformações expansivas. Com o intuito de buscarmos uma maior credibilidade ao estudo e de minimizarmos possíveis vieses, utilizamos distintos instrumentos de recolha dos dados, dentre os quais destacamos: os chats, fóruns, relatórios de trabalho e entrevistas que ocorreram durante o referido curso.

Durante o estudo das cônicas algumas possibilidades de transformações expansivas que poderiam estar relacionadas ao processo de moldagem recíproca nos chamaram a atenção. Determinadas expressões dos professores que indicavam a sensação de que algo nas soluções para os problemas usualmente encontrados em livros didáticos que tinham sido construídas por eles com a mídia lápis-e-papel estava incompleto nos deram o start. Esse tipo de sentimento surgia, na maioria das vezes, quando havia um tratamento distinto, uma separação, entre as soluções algébricas, que eles elaboraram com as mídias lápis e papel, e as construções geométricas iniciais que foram realizadas com o software.

Esse tipo de "separação" pode ser considerado uma configuração do que Engeström (2002) denomina de "encapsulação da aprendizagem escolar". Isso porque observamos o isolamento, a falta de relação entre as duas formas de representação das cônicas. Em outras palavras, os professores trataram inicialmente o estudo de forma compartimentalizada, em cápsulas. Essa forma de tratamento, ao que parece, já estava automatizada, internalizada por eles. Por outro ângulo, não podemos deixar de observar que nesse tipo de comportamento vem embutida uma contradição interna, que embora tenha ocorrido no sistema de atividade local, é estrutural e vem sendo historicamente potencializada pelo modo como aprendemos e ensinamos a matemática. Em termos do sistema de atividade local, que se constituiu ao longo do curso, romper com tais "cápsulas" significou superar essa contradição interna e transformar qualitativamente a produção matemática dos sujeitos. Verificamos que essas transformações não ocorreram de forma fortuita, ao contrário, o processo de moldagem recíproca indicou que as respostas dadas pelo software influenciavam nas ações futuras dos professores. Assim, é plausível concluir que o sistema de atividade foi 
protagonizado pelos professores em conjunto com o GeoGebra que por sua vez desempenhou distintos papéis.

No início do sistema de atividade ele exercia o papel de artefato e, quando a expansão ocorreu se tornou objeto, desse fato, a transformação expansiva do próprio objeto da atividade também aconteceu. Essa mudança de papéis do GeoGebra significou a transformação expansiva da própria produção Matemática dos sujeitos da atividade. 


\title{
Transformations and intershaping relationship in the On-line Mathematical Production with Software
}

\begin{abstract}
This article presents a discussion regarding the role of software in the possible transformations and in the process of intershaping relationship that can occur in the process of knowledge production. Specifically it addresses the occurrence of both during the math production of teachers using dynamic software GeoGebra to study Conic sections in an online environment. The theoretical background is based on the concept of Expansive Transformation, which comes from the Activity Theory, and the theorical construct theoretical human beings-with-media that discusses the notion of intershaping relationship. Data analysis is of qualitative nature and is based on the examination of empirical data produced in an online extension course offered by a Brazilian public University to mathematics teachers from Brazil and abroad. The results indicated that the transformations in the mathematical production by the subjects are inextricably related to the process in intershaping relationship and with the different roles that software exercised.
\end{abstract}

KEYWORDS: On-line mathematical production. Activity Theory. Humans-with-media. 


\section{NOTAS}

1 www.geogebra.org.

2 Artefatos (ferramentas e signos) no âmbito da teoria da atividade devem ser entendidos como meios mediacionais e referem-se à máquinas, escrita, fala, gestos, números, recursos mnemotécnicos, etc. .

3 Na próxima seção são apresentados maiores detalhes sobre essa ferramenta analítica..

4 Para uma leitura mais aprofundada sobre os trabalhos do GPIMEM recomendamos Borba e Chiari (2013).

5 Diferentes versões deste curso vêm sendo ofertadas pela Universidade Estadual Paulista "Júlio de Mesquita Filho" - UNESP, sua primeira edição foi no ano de 1993 e as edições que serviram como palcos da produção de dados desta pesquisa ocorreram em 2010 e 2011.

6 Esses problemas foram elaborados para coletivos de professores-comGeoGebra-internet-lápis-e-papel. A autora deste artigo em parceria com o prof. Dr. Marcelo de Carvalho Borba eram os docentes que ministraram o curso.

7 http://tidia-ae.rc.unesp.br.

8 Ao longo do texto ao nos referirmos ao "Minicilone de Transformações Expansivas" utilizaremos apenas "Miniciclone"..

9 Esse excerto destaca o momento em que os professores discutiam o exemplo 2, sobre o estudo da parábola, apresentado no início desta seção.

10 Vinicius se refere a construção que tinha o passo-a-passo.

\section{REFERÊNCIAS}

ARAÚJO, J. L.; BORBA, M. C. Construindo pesquisas coletivamente em Educação Matemática'. In: BORBA, M. C; ARAÚJO, J. L. (Org.). Pesquisa qualitativa em educação matemática. Belo Horizonte: autêntica, 2012.

BAIRRAL, M. A. Desenvolvendo-se criticamente em Matemática: a formação continuada em ambientes virtualizados. In: FIORENTINI, D; NACARATO, A. Cultura, formação e desenvolvimento profissional de professores que ensinam Matemática. São Paulo - Musa Editora. Campinas, 2005.

BORBA, M.C.; Students understanding of transformations of functions using multi-representational software. 1993, 372f. Tese (Doctor of Philosophy) Faculty of the graduate school of Cornel University. 
Tecnologias Informáticas na Educação Matemática e Reorganização do Pensamento. In: BICUDO, M. A.V.; Pesquisa em Educação Matemática: Concepções e Perspectivas. São Paulo: Editora UNESP, 1999.

; VILLARREAL, M. V. Humans-With-Media and the Reorganization of Mathematical Thinking: information and communication technologies, modeling, experimentation and visualization. v. 39, New York: Springer, 2005.

; MALHEIROS A. P. S.; AMARAL, R. B. Educação a distância online. 3ạ edição. Belo Horizonte: Autêntica, 2011.

DANIELS, H. Vygotsky e a Pesquisa. São Paulo: Loyola, 2011.

ENGESTRÖM, Y. Learning by expanding: An activity-theoretical approach to developmental research. 1987 (Helsinki, Orienta-Konsultit). Versão online, disponível em: http://lchc.ucsd.edu/MCA/Paper/Engestrom/expanding/toc.htm. último acesso 04/03/2011.

Learning by expanding: ten years after. 1999. Versão online, disponível em: http://lchc.ucsd.edu/MCA/Paper/Engestrom/expanding/toc.htm. Último acesso 04/05/2009.

Expansive learning at work: toward an activity theoretical reconceptualization. Journal of Education and Work, Vol. 14, N1, 2001.

GOLDENBERG, M. A arte de pesquisar: como fazer pesquisa qualitativa em Ciências Sociais. 10a Edição - Rio de Janeiro: Record, 2007.

HARDMAN, J. Making sense of the meaning maker: tracking the object of activity in a computer-based mathematics lesson using activity theory. International Journal of Education and Development using ICT- University of Cape Town, South Africa, (2007).

KAPTELININ, V. The object of activity: Making sense of the sense-maker. Mind, Culture, and activity. An International Journal. California, 2005.

LEONTIEV, A. N. O desenvolvimento do psiquismo. Livros Horizonte, Lisboa, 1978.

LÉVY, P. As tecnologias da inteligência: o futuro do pensamento na era da 
LINCOLN, Y.; GUBA, E. Naturalistic Inquiry. Londres: Sage Publications. Lisboa Portugal, Edições 70. 1985.

SANTOS, S. C. A produção matemática em um ambiente virtual de aprendizagem: o caso da geometria euclidiana espacial. 2006,135f. Dissertação (mestrado em Educação Matemática) - Instituto de Geociências e Ciências Exatas, Universidade Estadual Paulista "Júlio de Mesquita Filho" - UNESP. Rio Claro, 2006.

SILVA, M. Educação Online. São Paulo: Loyola, 2003.

SOUTO, D. L. P. Transformações Expansivas em um curso de Educação Matemática a distância Online. 2013, 279f. Tese (Doutorado em Educação Matemática) - Instituto de Geociências e Ciências Exatas, Universidade Estadual Paulista, Rio Claro, 2013.

Transformações Expansivas na Produção Matemática On-line. São Paulo: Cultura Acadêmica, 2014.

; ARAÚJO, J. L. Possibilidades expansivas do sistema seres-humanoscom-mídias: um encontro com a Teoria da Atividade. In: BORBA, M. C.; CHIARI, A (Org.) Tecnologias Digitais e Educação Matemática. Livraria da Física, São Paulo, 2013.

BORBA, M.C. Transformações Expansivas e tarefas Matemática em um universo que envolve Seres-Humanos-Com-Mídias. In: I Congresso internacional sobre a Teoria Histórico-Cultural e 11a Jornada do Núcleo de ensino de Marília. Marília: Oficina Universitária, v, 1. p. 1-15, 2012.

Miniciclo de aprendizagem expansiva em sistema seres-humanos-com-mídias e o fazer matemática online. In: XI ENEM - Encontro Nacional de Educação Matemática. Curitiba, 2013.

Seres humanos-com-internet ou internet-comseres humanos: uma troca de papéis? 2015 (manuscrito).

TIKHOMIROV, O.K; The psycological consequences of the computerization. In: Werstch, J. The concepto f activity in soviet psychology. New York: Sharp, 1981. 
Recebido: 29 de mar. de 2015

Aprovado: 05 de jun. de 2016

DOI: 10.3895/rbect.v9n1.2841

Como citar:

SOUTO, D. L. P. Transformaç̃̃es e Moldagem Recíproca na Produção Matemática On-line com Software.

Revista Brasileira de Ensino de Ciência e Tecnologia, v. 9, n. 1, p. 182-201, jan./abr. 2016.

Disponível em: <https://periodicos.utfpr.edu.br/rbect/article/view/2841>. Acesso em: xxx.

Correspondência: Daise Lago Pereira Souto

Rua A, S/N - Bairro São Raimundo, Barra do Bugres

Direito autoral: Este artigo está licenciado sob os termos da Licença Creative Commons-Atribuição 4.0

Internacional.

\section{(c) (1)}

